\title{
Islamification vs. Islamophobia: A Message to the Youth in the Occident: Critical \& Rhetorical Inquiries
}

\author{
Bahram Kazemian \\ Department of English, Tabriz Branch, Islamic Azad University, Tabriz, Iran \\ Shatha Naiyf Qaiwer \\ Department of English, College of Education for Women, University of Baghdad, Iraq \\ Shafigeh Mohammadian \\ Independent Researcher, Iran
}

\begin{abstract}
Drawing upon the recent theoretical framework of Burkean concept of identification (ID), the current study aims at probing the interaction of content and form in two letters penned by Iran's Supreme Leader and addressed to the Youth on Jan. and Nov. 2015. To this end, the study seeks (i) to determine a role ID takes in the conveyance of intended assumptions to the targeted readers; and (ii) to observe if the writer's objectives, i.e. to identify himself with the readers and to realize his politically-religiously-infused creeds, result in success or failure; moreover, (iii) it seeks to determine how he achieved his end to attenuate the impacts of blazing inferno of Islamophobia and anti-Islam sentiments in his addressees. The whole corpus (about 3000 words), in light of van Dijk's Socio-cognitive approach, is critically perused to seek out contextually-coded expressions. The study tries to set out a manner in which political text/talk could be analyzed rhetorically employing ID concept. It was found that ID as a two-way process is a key component for both parties to identify with. It makes the readers align themselves with the writer and helps the writer to associate with the readers and accomplish his goals.
\end{abstract}

Index Terms-identification theory, Burkean rhetoric, rhetorical strategies, socio-cognitive model, Mr. Khamenei's letters, Islamophobia, Islamification

\section{INTRODUCTION}

Language is a powerful shaping force in how we think about or negotiate our way through life. It is integral to the fabric of our daily life. Woods (2006) contends that in our everyday experience, we deal with people, we might need to convince them, or justify our actions to them. In our relationships, inevitably, we all need to write and explicate things to people or complain to them of unfair or unjust treatment. Alternatively, we may want to enforce power over people or grant power to them. Quite a lot of our activities, actions and learning are achieved through language. All the abovementioned activities, these social relations of ours, involve language (spoken/written); "most of them, in fact, are more or less wholly circumscribed by linguistic communication" (Woods, 2006, p. viii)

Ziahosseiny (1999) points out that both spoken and written discourse are dependent on context, addressee, and the relationship between speaker/writer and listener/reader. A natural communication may contain references impossible to decode without particular knowledge. Even written texts such as reports, letters and so on encode a high degree of shared knowledge between readers and writers. Thus, there are two main factors to be considered in communication whether spoken or written: explicitness and implicitness; that is, what there is to be mentioned, and what is implied or understood.

Politics and language go hand in hand and are closely interwoven and intimately linked at a fundamental level (Chilton, 2004) that, as Lakoff (1990, p. 13) put it, "politics is language and, at the same time, language is politics". Nowadays, with the increasing globalization and cross-cultural communication, people are more interested in political discourses and due to the great impact of politics in our everyday life and of its pre-arranged and engineering essence for public consumption, this discourse has gained its prominence and value worldwide (van Dijk, 2001). The most remarkable and distinctive characteristics that differentiate political discourse from other sorts of discourses are their strong relations with power and control and their multiple and discursive purposes worldwide and nationwide (Zhou \& Kazemian, 2015).

Political pundits and statesmen, on the one hand, often attempt to introduce themselves as an authority in order to exert power and influence upon the addressees, as well as to steer grassroots' viewpoints and thoughts to conduct in distinct ways etc. On the other hand, they need to attenuate their power, in one way or another, so as to create a desirable associations and identification with their addressees. All of the above properties make the political discourse 
more intricate and discursive and it merits our particular and rigorous attention. In using language in different contexts and discourses such as politics, advertisement and so on, rhetoricians tend to employ particular forms of language to convey particular meanings and assumptions to various people with various orientations and beliefs at one time and within one piece of discourse; therefore, their utterances have a certain force and have consequential effects on the addressees (Woods, 2006, p. vii; Kazemian \& Hashemi, 2017).

\section{Objective \& Significance of the Study}

This study is an attempt to set out a manner in which a written/spoken discourse in politics, advertisement etc. could be analyzed and appraised lexico-grammatically, critically, and rhetorically through content and form employing Burkean concept of Identification along with its various strategies, tropes and functions. Put in other terms, the study seeks to pinpoint a role Identification (hereafter ID) takes in the conveyance of intended meaning and assumptions to the targeted readers by the writer, and in this underlying trend and effort, to observe if his ends and objectives to attenuate Islamophobia and Anti-Muslin sentiments amongst the youth culminate in success or failure; It also seeks to see if he succeeds in identifying himself with his addressees, transcending division, inducing cooperation and, thus, realizing his politically, religiously-infused creeds, purposes and notions in the letters.

The significance of the corpus for analysis is that it is the first time that young people in the Occident have been directly addressed by a senior Islamic cleric about Islamic thoughts and teachings, Islamophobia and Anti-Muslims propaganda aroused by the Occident's media and pundits. And also, neither in this framework nor other linguistic disciplines, the letters have not been critically, attitudinally and rhetorically evaluated or inspected in any academic papers except for some reviews in online magazines and newspapers by critics.

The significance of the theoretical discipline applied in this study is that Burkean Identification theory is a relatively recent line of thinking within rhetoric and political discourse. Since ID arises from the interaction of content and from (Foss, Foss, \& Trapp, 2001; Zhou \& Kazemian, 2015), the corpus is analyzed from two angles: ID strategies from rhetorical content and form; see the following proposed Table (1) as a rhetorical model to investigate political or any other discourses through Identification Theory (ID-Th in short) each of which will be discussed in the following section.

TABLE 1.

A PROPOSED RHETORICAL MODEL OF ID ANALYSIS IN POLTTICAL OR OTHER DISCOURSES:

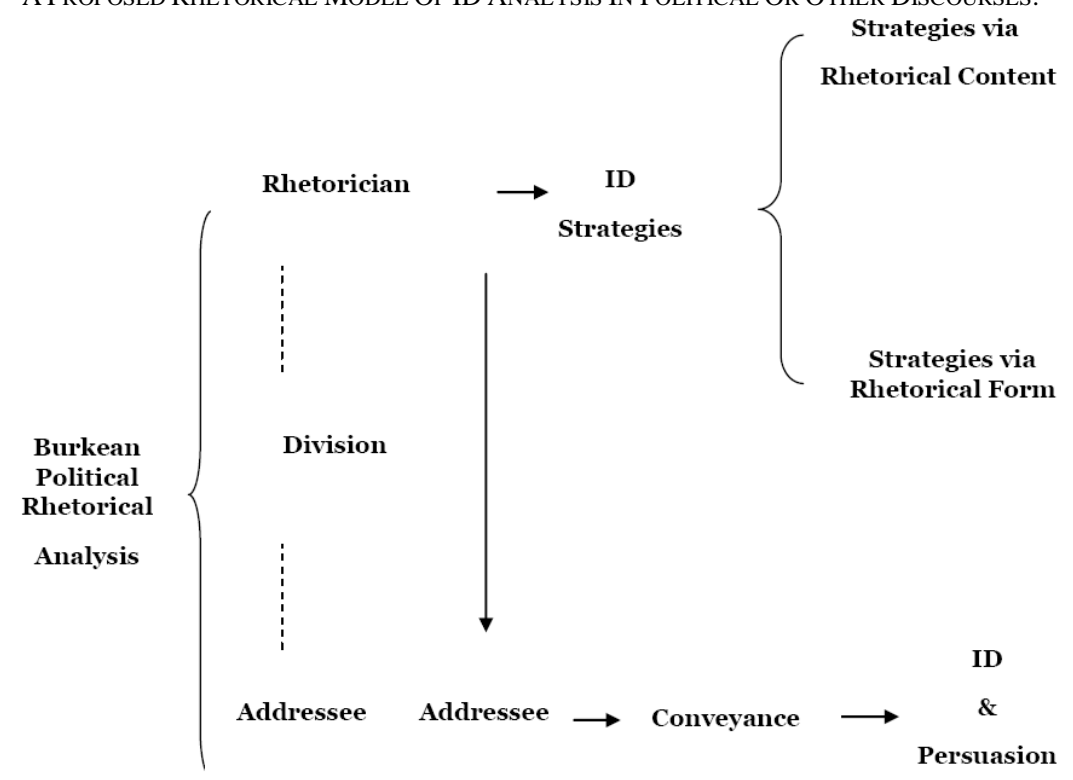

Surveying preceding and recent annals of literature involving ID-Th in new rhetoric shows that their focal attention mainly fixed on the elaboration of Burkean concept of ID and its types, tropes and components (Griffin, 1952; Weaver, 1953; Rosenfeld, 1969; Ambrester, 1974; Ehninger, 1975; Harte, 1977; Bitzer, 1980; Cheney, 1983; Hansen, 1996; Corbett, 1998; Foss, et al, 2001; Richardson, 2004; Johnstone \& Eisenhart, 2008 etc.); while little has been expressed about how ID-Th in Burke's new rhetoric (Sinha \& Jackson, 2006; Christiansen, 2014; Li \& Chen, 2015 etc.) could be practically exploited for critical and rhetorical evaluation in various genres and discourses. Furthermore, in spite of ID's clear association to persuasion and inducement of attitudes and actions, as outlined by Burke (1969a, b), few studies (Rex, 2011; Zhou \& Kazemian, 2015) have applied ID to the realm of political discourse whereas huge quantities of research investigated old rhetorical tropes in various discourses (Flowerdew, 2002; Murphy, 2003; Atkins \& Finlayson, 2014; Kazemian \& Hashemi, 2014, 2017 etc.). This is dispiriting since the rhetoric of politics is a fundamental and an indispensable part of the communication discipline.

\section{THEORETICAL FRAMEWORKS}




\section{A. ID Theory in Burkean Rhetoric}

According to Burke (1969a) "the most characteristic concern of rhetoric is the manipulation of men's beliefs for political ends" (p. 41). He adds that the underlying function of rhetoric is "the use of words by human agents to form attitudes or to induce actions in other human agents" (p. 41). To Burke (1969a), rhetoric "is rooted in an essential function of language itself, a function that is wholly realistic, and is continually born anew" (p. 43). He states precisely that "rhetoric is the use of language as a symbolic means of inducing cooperation in beings that by nature respond to symbols" (1969a, p. 43). That is to say, rhetoric is an added incentive to action. By means of inducement, the grassroots can be rallied and can create incentives to act in intended ways.

Burke then develops the definition of rhetoric by presenting the conception of ID into new rhetoric. Rhetoric, for Burke, is an intricate concept of meaning, persuasion and human interaction established on ID/consubstantiation as the quality of sharing attributes. Rhetoric copes with language's role in ID, influence and inducement of viewpoints and actions. Thusly, the key term in Burkean rhetorical theory is ID which is rooted in the notion of substance (Sinha \& Jackson, 2006). Identities or selves are formed through various properties or substances. According to Herrick (2013), ID is the key to persuasion; "as we share substances, we come to identify with others. As we speak each other's language, we become consubstantial" (p. 174). Burke utilizes ID to appraise the traditional concept of rhetoric as persuasion.

In this way, accomplishing ID with 'the other' for Burke is nothing more than being "united in substance through common ideas, attitudes, material possessions, or other properties, that is, to be consubstantial with the other" (Foss et al., 2001, p. 158). It is through the motives of property in which a thing is identified; i.e. objects, groups, and even ourselves are identified through their substance. Burke (1969a) maintains that via a rhetorical appealing to substance, ID and ultimately persuasion can be achieved. Just as he exemplifies: "to identify A with B is to make A 'consubstantial' with B" (Burke, 1969a, p. 21). To put it simply, whenever someone strives to induce and persuade someone else, ID occurs; for persuasion to occur, one party must identify with another. That is, the persuaded one notices that one party is like another in some way. Within Burke's theory, division between two parties is essential for ID to occur, as he says: "identification is affirmed with earnestness precisely because there is division. Identification is compensatory to division" (1969a, p. 22). Thus human beings consist of a unique compound of different substances, and because of this uniqueness, there are divisions amongst them.

The introduction of the key terms by Burke viz ID versus division (alienation/ dissociation) in his theory deserves particular consideration. He proposed that ID should be the central concern within the new rhetoric (Burke, 1951). He concurs with Aristotle's remark that ID can be a process of persuasive appeal "as when the politician seeks to identify himself with his audience" (Burke, 1951). ID in this regard is a plea to the rhetoricians' ethos. However, Burke's initial concern in ID is that it can be an end in itself as when people solemnly long to identify themselves with some group or other (Burke, 1951).

Burke (1951, 1969a, b,) discriminates the old rhetoric from new rhetoric, and proposed that the key term for the latter is ID whereas the former concentrates more on persuasion. He suggests that as for the association between ID and persuasion, the rhetoricians struggle to persuade their addressees by the exploitation of stylistic IDs; the act of persuasion is carried out for the purpose of causing the addressees to identify themselves with the rhetoricians' interests and assumptions; in other words, they draw on ID of interests to create relationship between themselves and their addressees. Therefore, rhetoric for Burke becomes diverse patterns of attaining ID (Burke, 1969a, b; Corbett, 1998). In his seminal book, Burke (1969a) identifies three major types/functions of ID-Th as:

1) ID via common goals/background as a means to an end, primarily functioning as persuasion,

2) ID through common enmity/challenge, i.e. establishing ID over a joint enemy in association with a mutual enemy,

3) ID through unconscious association (Burke, 1969a; Herrick, 2013).

The scope of rhetoric in Burkean theory embraces both traditional and non-traditional tropes and forms of discourse. This first type is a more traditional procedure to rhetoric and ID in which rhetoricians draw the addressees' attention with the primary objective to influence and win their full support; it is primarily utilized as a means to an end to achieve some degree of persuasion between the rhetoricians and the addressees. This type of ID is very prominent in essence, where rhetoricians try to achieve consubstantiality by identifying their personal properties/substance with the properties of the addressees.

In Burkean theory, the $2^{\text {nd }}$ type is titled ID via Antithesis in which ID can be attained amongst joint enemies through the sharing of a mutual enemy. When ID is achieved among enemies through the association of a common enemy, two opposing parties can get united via some form of mutual opposition. Again, this type of ID serves a prominent role as a linkage between enemies out of a desire for common benefit. ID here operates as an association via a mutual antithesis, bringing together parties or individuals who traditionally would not work and operate together. Burke's $2^{\text {nd }}$ type of ID function is perchance summed up best by the old proverb, "the enemy of my enemy is my friend" (Christiansen, 2014, p. 32).

Finally, there are instances where we might not be fully conscious of the IDs we are making and may hold within our subconscious. The third and final type of Burke's conception of ID, and often the most influential, is where ID can accomplish subconsciously or is utilized to persuade the addressees at an unconscious level (Foss et al., 2001).

\section{B. Van Dijk's Socio-cognitive Approach}


Van Dijk (2001) asserts that "action is controlled by our minds"; thus if we can sway people's minds - for instance, their worldviews, outlooks, or ideologies- "we may control their actions, as we know from persuasion and manipulation" (p. 355). He (2008) also claims that contextualization plays a crucial role in our perception of human conduct and that discourse is never totally explicit and has several meaning implications (entailments) that are not directly and clearly delineated by discourse producers. The rationale behind it is that discourse producers presuppose that their addressees have a large quantity of general sociocultural knowledge and are able to imply these coded propositions on the basis of generally shared knowledge, and thus perceive a mental model for the discourse.

Two vital features of discourse meaning, for van Dijk (2008), are its presuppositions and entailments. Implications at times are made hidden due to communicative or interactional reasons explicable in contextual terms; for instance, discourse producers do not tend to claim responsibility for explicitly stating such propositions, that is, "as a form of self-protection or positive self-presentation" (p. 148). Van Dijk (2008) adds that contextual inspection of discourse should go beyond grammatical, textual and interactional analysis or understanding. We do not appropriately perceive complicated phenomena without apprehending their context. Construing discourse means discerning 'text/talk-incontext'.

\section{METHODOLOGY}

\section{A. The Dataset \& Context}

It is assumed that familiarity with context can assist readers in comprehending coherent relations across text/talk. To date few studies embarked on analyzing Burkean ID theory in political discourse. This analytical, theoretical and rhetorical discourse study seeks for the interplay between ID-Th in Burkean new rhetoric and two letters penned by Iran's Supreme Leader, Ayatullah Seyyed Ali Khamenei, and addressed to the Western Youth on Jan. and Nov. 2015. Due to their international political salience, two letters, approximately 3000 words, are selected to pinpoint ID functions and strategies through rhetorical content and form (see Table. 1). The $1^{\text {st }}$ letter is titled 'To the Youth in Europe and North America' and is penned on Jan. 2015 available at (http://farsi.khamenei.ir/ndata/news/28731/index.html\#en). The $2^{\text {nd }}$ letter is written on Nov. 2015 and titled 'To the Youth in Western Countries' available at (http://english.khamenei.ir/news/2681/).

To counter the Western media's Islamophobic propaganda and in response to the Charlie Hebdo's terror attacks in Paris on 7 Jan. 2015 by some Muslim militants who claimed responsibility for shooting, Ayatollah Khamenei has penned an open letter to Western youth. The $2^{\text {nd }}$ letter was also penned by him in response to the November 2015 Paris parallel attacks and other contemporary terrorist actions, such as the attack and crash on the Russian plane and the 2015 Beirut bombings. Both letters deal with Mr. Khamenei's views on the causes of recent terrorism. They concern with a quite disturbing increase and cogent manifestations of Islamophobia and Anti-Muslim sentiments, which have further been escalated in the aftermath of the recent terrorist attacks in Paris. The letters were prompted via his accounts on various social media, including Twitter, Facebook and Instagram, using the hashtag \#CommonWorry attributed to Mr. Khamenei.

The letters denounces the Western media's depiction of Muslims as terrorists in the wake of Paris terror attacks and called on the Youth to construct their own impartial and independent understandings of Islam rather than the media alone, which he believes it is imperative after several struggles in the last twenty years 'to place this great religion in the seat of a horrifying enemy'. In both letters, Mr. Khamenei sets forth definite requests for those reading the letters: 'Study and research the incentives behind this widespread tarnishing of the image of Islam' and he appeals to the Western Youth to have an open mind when it comes to Islam and not to assess it based on the Charlie Hebdo shooting or other violent terrorist attacks. He implores Western youth, in both letters, to learn about Islam from its original sources, rather than have it 'introduced through resentments, prejudices' and Islamophobia.

\section{B. Procedure}

The current work first aims to explore the interaction of content and form in the corpus in light of Burke's concept of ID. The initial focus is on ID functions in rhetorical content, i.e., ID via common goals/background as a means to an end, ID via common enmity/challenge or ID through antithesis, and ID through unconscious association. Then, the corpus will be analyzed through ID strategies of rhetorical form, namely, conventional form and figurative forms (minor rhetorical forms) such as parallelism, three-part list, rhetorical questions, reversal and antithesis etc. which are employed by Mr. Khamenei (the writer) in the letters, as the more salient features. Those strategies are going to be studied to see how he uses a series of ID strategies, consciously or unconsciously, to identify himself with his addressees, to persuade, to sway and control their minds (see Table 1), as well as it seeks to determine how he achieved his end to attenuate the impacts of blazing inferno of Islamophobia and anti-Islam sentiments in his addressees.

While perusing the intended corpus for possible functions of ID, the researchers noticed a large number of contextually-implied expressions in both letters and decided to critically sift through those implied expressions based on van Dijk's analysis (2008) of contextually-coded expressions in Socio-cognitive approach. To this end, the study adopted and applied Stanovich's (1980) interactive-compensatory model of analysis with a functional orientation to interpret the corpus with undivided attention, and in light of van Dijk's Socio-cognitive approach (2008), both letters are critically perused to seek out and unravel contextually-coded expressions, hidden meanings, discursive and intended 
orientations, ideologies produced and deployed by the writer or his spin doctors in the corpus. Considering its general purposes and the corpus, this study hopes to be regarded as a step in a rather new direction and a bid to probe any text and talk in various genres and discourses utilizing the extended tools of ID-Th in Burke's new rhetoric.

\section{RESULTS AND DisCUSSION}

\section{A. Strategies through Rhetorical Content}

Rhetoricians deploy various linguistic strategies in their discourse giving clues to the addressees that their properties are alike in many ways, achieving ID and thereby attaining persuasion. In short, ID is persuasion and influence. It is important to note that persuasion and influence are viewed as synonymous terms, where influence is a process that leads to persuasion. As Burke highlights, in achieving persuasion and influence, the rhetoricians must first engage to carry out ID (Christiansen, 2014).

\section{ID as a Means to an End via Common Goals}

In Burke's initial type, ID is functional and operates to attain a particular end and objective, serving to aid in the influence and/or persuasion of another party or group. It is worth noting that ID is a bilateral process, where first ID strategies must exist within rhetorical discourse, i.e. in order for ID devices to be effectual not only must the devices exist but also must they be linked with the readers' sub-consciousness and thereby hold them as parts of their identity. The writer in both letters struggles to depict a plurality of personal properties, values and outlooks as common goals; by depicting and invoking these values that seem common amongst all people worldwide, ID can occur and his effort can be a success in achieving ID and persuasion.

These expressions and values of 'building a better and safer future, terrorism as our common concern, sympathy with the victims, pursuing security \& peace, eager for cultural interactions, inspiring confidence and trust in the youth etc. in both letters are apparently positive characteristics that we as human beings strive to attain them in our personal and public lives and can help the writer to identify with his intended readers. This direct listing of personal values in letters can assist him in highlighting his rhetorical and symbolic properties for his addressees to identify with. In doing so, he symbolically positions his readers in a situation to assess and establish their own moral values and properties, and via this appraisal process, the readers determine to identify with or against the writer's notions and attitudes. Consider the following excerpt from the $2^{\text {nd }}$ letter:

1) 'Anyone who has benefited from affection and humanity is affected and disturbed by witnessing these sceneswhether it occurs in France or in Palestine or Iraq or Lebanon or Syria'.

The above excerpt is the epitome of a sympathetic and passionate statement expressed by him to portray his personal properties over the victims; it can be tailored to meet the properties of readers resulting in ID. This ID type is intended to achieve a particular goal and is performed best by the following excerpt as the key property in $2^{\text {nd }}$ letter which is highly motivated and impassioned: 'It is correct that today terrorism is our common worry'.

By voicing his concern at terrorism and by implicitly deprecating and abhorring terrorism throughout $2^{\text {nd }}$ letter, it enables him to explicitly assert his intentions and his end he is struggling to accomplish. It is an indirect ID plea to the readers by appealing and stimulating them to stand on his side against terrorism. It also creates a positive face that allows for his readers to accept or reject these portrayed properties. By rhetorically opining properties that align with the objectives and intentions of the addressees, ID as a means to an end can accomplish between two parties. Through his symbolic focus on terrorism, he can identify his notions with the readers and induce their co-operation as well; and through the readers' ID with him, he can garner their support and ultimately achieve his goal.

However, it might result in total failure in attaining ID and persuasion by some readers through his successive remarks (in $2^{\text {nd }}$ letter, par. 4). The rationale for his possible failure is that, instead of direct deprecation of violent tumor of terrorism in Paris and overt sympathy with the victims, he strives to compare those atrocious terrorist attacks with the ones in Islamic world. He states that those terrorist groups are West-sponsored and West-recruited acting as proxy for them.

\section{ID via Antithesis or a Common Enmity}

ID by antithesis is the most overriding part of attaining congregation via segregation; in other words, ID in Burkean theory occurs when foes unify against a joint enemy. The separation here implies the antithesis. Due to having a common enemy/obstacle, both parties become allies and work together in order to conquer this new stronger and mutual enemy. This external enemy noticeably provides an incentive for these two opposite parties to congregate (Li \& Chen, 2015).

This type of ID is very functional in essence provided that it is implemented appropriately and in full. Strategically, the writer can gain ID by mentioning the mutual enemy between two parties; displaying a mutual sharing of properties between the parties makes them consubstantial. In a bid to gain ID through unification from a joint enemy, both parties will be integrated through such a joint rival. Thus it enables the writer to place himself in a desirable position to attain his political desires and objectives.

By dint of a plurality of common vices and enemies in both letters such as horror and hatred, insincerity and hypocrisy, the oppression of people of color, bloodshed, humiliation, brutality, death and destruction, torture, extremism, violence, aggression, corruptions and so on, the writer is able to attain ID and commonality through mutual 
threats and obstacles with the readers. By establishing ID through the attachment of these common concerns, two opposing parties become integrated into mutual oppositions and vices, and consequently, ID occurs.

The writer attempts to accomplish this type of ID by manifesting and introducing himself as a leader fighting against these international threats and vices. These threats are common enemies of all the mankind which are utilized to gain ID with his addressees via antithesis. This type of ID is performed and achieved best in the $2^{\text {nd }}$ letter by expressing and depicting his concerns over such threats as 'terrorism, violence, oppressions, insecurity etc. as our common worries', which are regarded as joint enemies for all people worldwide. ID here operates as a bond or togetherness through a common antithesis, bringing them together to unify and function together against mutual threats.

However, he is unsuccessful to achieve ID through a common enemy in the $1^{\text {st }}$ letter, because despite the fact that the letter is written in response to the horrifying violence of Paris terrorist attacks, he doesn't explicitly condemn terrorism and violence at all and in return, he attributes those atrocities by the terrorist groups to the Occident's contradictory policies against terrorism. He even does not bother himself to name the word 'terrorism' and instead says that 'the recent events in France and similar ones' have convinced me to talk and write to you about Islamic thoughts, AntiMuslim sentiments, and Islamophobic propaganda aroused by the Occident and the mass media affiliated to them.

\section{ID via Unconscious Association}

The final strategy in both letters is the appeal to common values and beliefs which falls within the $3^{\text {rd }}$ type in ID-Th. This last function of ID is gained through the motives of subconscious, i.e. ID is achieved without awareness or willful intent. There are sometimes examples where we might not be conscious of making the IDs and may hold within our subconscious named by Burke (1969a, b) as the subconscious component of ID.

As human beings there are instances we may identify with individuals, groups, practices, or states of affairs in which we might not utterly perceive why. This inexplicable bonding to certain objects, groups, or individuals, Burke says, is explicated by the subconscious type of ID. Now In rhetorical domain, by dint of the rhetorical 'we-group' vs. 'I-group' strategy, rhetoricians can achieve an unconscious form of unification amongst the addressees. Cheney (1983) argued that from a writer-reader perspective, the exploitation of the rhetorical strategy, i.e. 'we-group' vs. 'I-group', can assist in stimulating an unconscious form of unification and cohesivation amongst the addressees. Burke (1969a) emphasizes that this sense of unification and belonging is rhetorical in essence.

In the $2^{\text {nd }}$ letter (par. $4^{\text {th }}$ ), Mr. Khamenei mentions that 'terrorism is our common worry', and by dint of we-group (12 times in $2^{\text {nd }}$ letter), he has constructed an inclusive relation between himself and his readers. He has strategically united and included himself in the same group to shorten his distance between them, and then to share and convey his politically- and religiously-charged creeds and notions to them. On the whole, the above clause seems very impressive and effectual which is deployed to create joint intimacy, sympathy and rapport with the addressees (Kazemian \& Hashemi 2017). As a result, respecting Burke's $3^{\text {rd }}$ type of ID, he is successful in establishing subconscious ID with the readers in $2^{\text {nd }}$ letter.

However, since he has not utilized any we-groups in the $1^{\text {st }}$ letter and instead has used you-groups and I-groups in large quantities, perchance his efforts in subconsciously identifying with the readers culminate in failure. This $Y O U$-DoAs-I-Command-Trend in the $1^{\text {st }}$ letter (40 you-groups and 13 I-groups) has made him and his words tough, unapproachable, and hard as well for the readers to become consubstantial and subconsciously identify with him. Thereby, based on Burke's $3^{\text {rd }}$ type of ID, a division/lack of ID remains between two parties in $1^{\text {st }}$ letter.

At the very beginning, the writer in $1^{\text {st }}$ letter states that '... the sense of quest for truth is more vigorous and attentive in your hearts'; meaning to create ID with his addressees, he has drawn upon certain key words, such as 'truth, security, peace' and the like to relate his properties with the properties of the addressees. These values (quest for truth, security, bright future, peace etc.) are stated repeatedly in different forms throughout the letters along with some other common values in the corpus.

The sense of peace, security and truth is cherished by people from all walks of life worldwide. By appealing to these common values, he may have achieved the favorable ID and impression from the domestic readers, the Western youth as well as most Muslims worldwide. These are common values shared by peoples all over the world, whatever their cultures, religions and social backgrounds. Consequently, he might win the appreciation and trust of most youth and Muslims nationwide and worldwide in this regard. These keywords and expressions can unite the writer with that of his addressees, establishing a sense of belonging and unification. As Burke contends 'belonging' is in a sense rhetorical (1969a).

In addition to the above-mentioned values and beliefs, he has also resorted to the religious motifs or the adherence to God. For example, he has commenced his letters with the name of God (In the name of Allah, the Beneficent the Merciful) which enunciates his religious faith. Besides, there are also some other strong religious contents disseminated through his speech which all can help him to win the sympathy and supporting of the readers and identify with. Insofar as the emotional appeal, he can place ID and associate the properties of religious motifs with both Muslims and the Youth worldwide.

Eventually, to condemn the callous slaughter of hundreds of innocent civilians by terrorists, Israeli soldiers' brutality with Palestinians, and to attack the West and their mass media for Anti-Muslim sentiments, as well as their doublestandard and inconsistent policies against terrorism, the writer has employed vast quantities of Devil Terms in both letters. Hence, the plurality of Devil terms in both letters can adversely affect the unification and ID of some readers 
with him. These informationally and lexically-loaded sentences with devil terms as well as their coercive power and pejorative meanings throughout the letters, can provoke a sense of alienation amongst some readers from the letters and the writer and inevitably culminate in dissociation/division between two parties.

\section{B. Strategies via Rhetorical Form}

In rhetorical form, there are three major types of form, or processes of generating persuasion and effects as (i) conventional form (subdivided into (a) typical structure of text/talk, (b) stylistic features of text/talk, (ii) repetitive form (the use of redundancy or restatement of common values and beliefs) and (iii) progressive form (which guides the addressees to anticipate or desire certain developments). The progressive form is not considered in this study. There is also a plurality of minor rhetorical forms named as figurative forms in traditional rhetoric, such as the metaphor, paradox, reversal, rhetorical questions and so on. The stylistic features of text/talk in conventional form refers to the appropriate deployment of short and long sentences; a great variety of sentence types not only lead to the expressive power of text/talk, but also help the rhetoricians fulfil the addressees' anticipatory expectations of form and pattern of text/talk (Zhou \& Kazemian, 2015). Thus, they can be utilized to accomplish ID with the addressees as far as the conventional form concerned (see table $1 \& 2$ ).

\section{Conventional Form}

In Burke's sense, a rhetor "can't possibly make a statement without its falling into some sort of pattern, any consideration of the subject or content of rhetoric also must include a consideration of its form" (Foss et al., 2001, p. 194). Conventional form in Burke's theory is the expected process utilized to craft rhetoric. It is categorized as one of ID strategies via the rhetorical form. Rhetorical form and content are of equal importance to rhetorical acts. Form is the preliminary thing that the readers encounter a discourse.

Compared with traditional rhetorical from, both letters are at odds with the typical structure and format of the letter writing. The length of both letters are not on a par with the typical pattern of letter writing format $\left(1^{\text {st }}\right.$ letter is about 1000 words and the $2^{\text {nd }}$ one about 2000 words). The $2^{\text {nd }}$ letter is too long and extended and is pregnant with tedious and redundant information. They are both comprised of a title but lack the opening part and greetings. They contain introductory paragraphs, the body parts, the writer's politically and religiously-charged creeds and notions and the closing remarks as well.

They are not well-organized and they do not show great coherence and rationality in terms of content and arguments. They contain quite a few indirect, covert and implied remarks so that it might be hard for the readers to digest and take the writer's intended concepts and assumptions in, and therefore, difficult for them to align and identify themselves with the writer. It may be difficult for the writer as well to encourage the readers to embrace and support his policies. It is assumed that the neater the organization of text/talk, the better their readability and reliability as well. Through rigorous arrangements of the letters and arguments, the readers can show inclination toward cooperation and can identify with the writer unconsciously (Zhou \& Kazemian, 2015). For a quick review and synopsis of the $2^{\text {nd }}$ letter, please see Appendix or visit (http://english.khamenei.ir/news/2684/).

\section{Figurative Form: Rhetorical Tropes}

Day (1960) contends that ID in Burkean rhetoric is a process leading to persuasion and it covers all the traditional tropes of rhetoric as a set of apparatus to create ID within rhetorical discourse. To Burke (1969a), all rhetorical tropes in ID-Th are not solely used for persuasive purposes as in the traditional rhetoric, but they are subconsciously or intentionally exploited by rhetoricians to transcend division, gain ID, induce cooperation, and thus, to realize their motives with their addressees. To this end, if rhetoricians tend to make their text/talk more forceful and persuasive, they would resort to the figurative use of language (Day, 1960). For Burke all the traditional rhetorical devices are a means of establishing ID, and ultimately persuasion (Harte, 1977).

In both letters, many traditional rhetorical tropes are employed such as parallelism, three-part list, Rhetorical Questions, Reversal and Antithesis each of which will be clearly delineated as follows. Initiated for persuasive effect and in part for aesthetic impact, rhetorical tropes viz parallelism and tree-part listing include instances of syntactic and lexical patterning of language which adds melodic-like and cohesive structures to the letters (Kazemian \& Hashemi, 2014, 2017). Done well, parallel structures can convey influence, harmony and power to text/talk. They also adds balance, rhythm, and, most importantly, clarity to the sentences. As an example, this structure ('Have you ever ...') in $1^{\text {st }}$ letter has been used five times in a row to holds the readers' attention right to the very end and to display that the ideas and arguments are equal in importance. Consider another example as in:

1) UNTIL double-standards dominate ..., UNTIL terrorism is divided into 'good' and 'bad' types, and UNTIL governmental interests are given ..... ( $2^{\text {nd }}$ letter $)$.

These parallel and repetitive structures along with three-part listing are not only helpful to explain the writer's ideas in a forceful way, but more importantly, beneficial and pre-planned to impress the readers. Thomas \& Wareing (2004) argue that "audiences and speakers seem to find linguistically grouped features and especially those in threes, aesthetically pleasing" (p. 49). Rhetorically, by exploiting repetitive structures and the rule of three in logical sequences, not only can they add clarification, unification, efficiency and beauty to the sentences, but they are also readily embedded and stuck in the addressees' mind (Woods, 2006; Kazemian \& Hashemi, 2017) as in:

2) Therefore, don't miss the opportunity to gain proper, correct and unbiased understanding

3) They result in growth, development and richness. 
They can also establish 'the familiar clap-trap rhythm' that the addressees can identify them as both persuasive and appropriately political (Woods, 2006, p. 57). Two other rhetorical strategies analyzed in the corpus are the abundant utilization of Rhetorical Questions (RQ hereafter) and Antithesis which can help the writer to strengthen his rhetorical impact and emotive force of his oratory.

By dint of these preplanned RQs in both letters, he is trying to steer the addressees to the main issue and to his requests that he wishes to communicate to them from paragraph eight in $1^{\text {st }}$ letter and from paragraph ten in $2^{\text {nd }}$ letter; as part of this, he urges them to seek and to attain a firsthand knowledge of Islam, rather than accepting his own or any other reading of the religion or the media alone. He also strongly recommends them to read and learn the Quran for themselves in para. 13 in $1^{\text {st }}$ letter. These RQs can form nicely developed paragraphs by changing a series of logical propositions into queries. As one of the persuasive devices in rhetoric, RQs are utilized by the writer to primarily convey his purposive notions to the readers and then to make them contemplate on issues as well. Indeed, they are not all replied by him, for their answers are apparent or apparently desired, and usually just a yes or no. The writer has posed seven RQs in $1^{\text {st }}$ letter and 11 in $2^{\text {nd }}$ letter and has obliged the Youth to ponder over the targeted phobias and illusionary fear of the Islam by the super powers. These long and complicated RQs are mostly utilized in both letters in a row which can constitute highly sophisticated and directed paragraphs by rendering a series of rational propositions into inquires, enabling the addressees/readers to contemplate, enquire or even reach a conclusion along with the orator as well.

To Abrams \& Harpham (2009), Antithesis is defined as a "contrast or opposition in the meanings of contiguous phrases or clauses that manifest parallelism" (p. 14). By dint of reversal and antithesis in the text, the writer can put all his propositions in two different situations as in:

4) Fissures have to be sealed, not deepened,

5) ... analyses that see the hidden and apparent corruptions.

6) ... is divided into 'good' and 'bad' types.

By this contrast, the addressees might be more responsive to his suggestions, and consequently, much more likely to identify and agree with him. These antithesis and reversal tropes (24 clauses) in both letters are subconsciously or deliberately and strategically juxtaposed to indicate inconsistent propositions and to help the readers distinguish facts from fictions, falsehood from truth and so on (Kazemian \& Hashemi, 2017).

TABLE 2

IDENTIFICATION FUNCTIONS \& STRATEGIES IN MR. KHAMENEI’s POLITICAL LETTERS

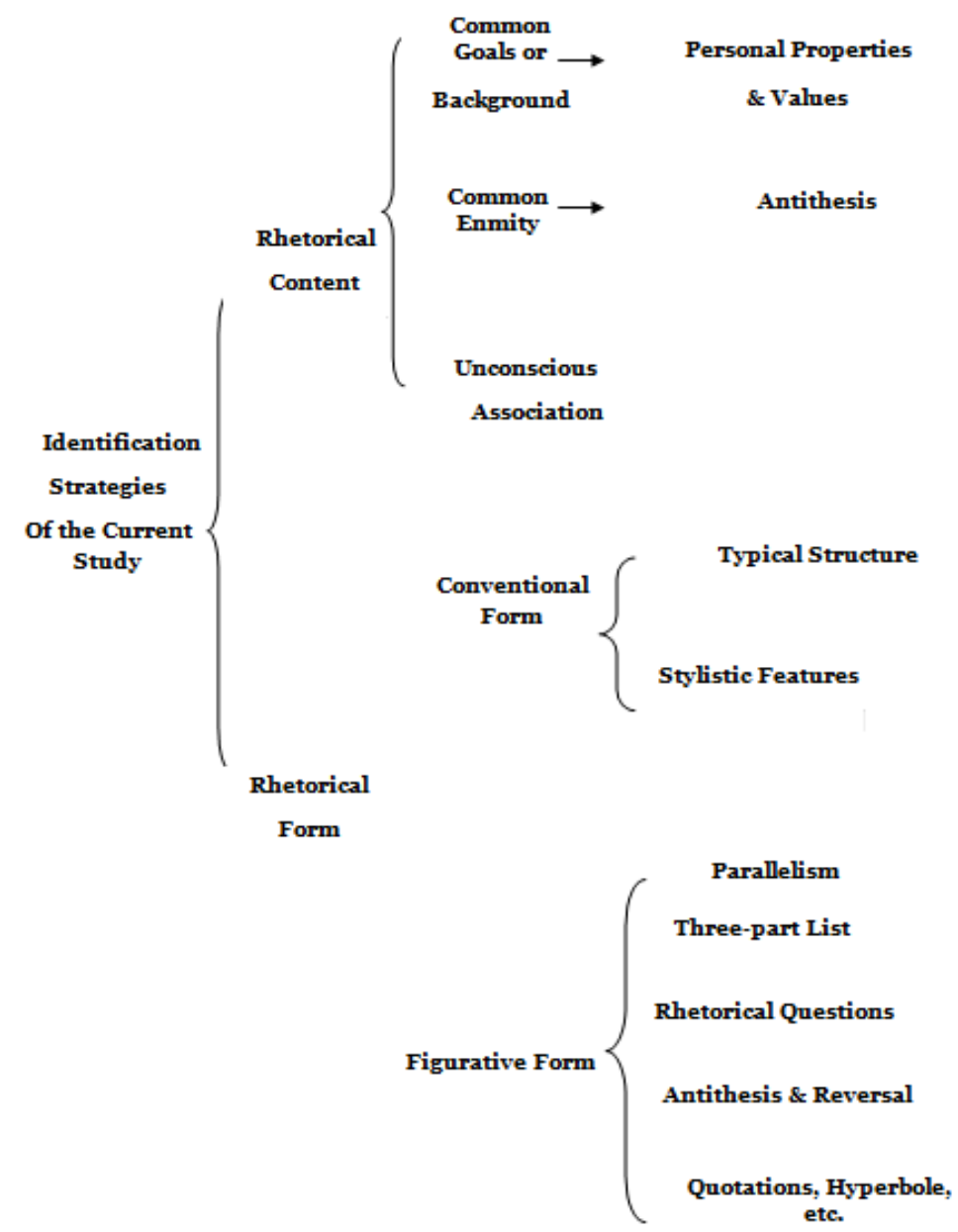


By dint of various properties and values as well as traditional rhetorical tropes and strategies, the writer is in a bid to align his rhetorical properties and expressions, either real or perceived, with that of the addressees. By deploying various keywords or phrases, for instance, through rhetorical tropes, the writer is able to draw on the perceived ideals of the political culture.

\section{Critical \& Contextual Analysis of the First Letter}

To van Dijk (2008), the prevailing perception of context-discourse relations is that "it is context that influences (controls, etc.) discourse" (p. 128); the reverse also holds true but it is pretty rare in which discourse controls context. Respecting the context and setting of the letters, both letters are separately perused in light of van Dijk's Sociocognitive approach to unravel contextually-coded expressions and words as follows.

The writer has long mentioned his animosity is directed not toward the American people but at their government. In keeping with that concept, at $1^{\text {st }}$ and $2^{\text {nd }}$ paragraphs, he writes that his letter 'isn't addressed to Western leaders', whom he accuses of intentionally distorting the truth, but to the youth who might still have open minds. As part of this, at the outset of the $1^{\text {st }}$ letter (par. 2) and $2^{\text {nd }}$ letter (par. 3), he explicitly and aggressively accuses and censures the West for deviation from the path of righteousness and virtuousness. To this end, he probably endeavors to convince the youth to ruminate over his following pointers and remarks, and to turn and hold their attention to the crux of yawning chasm and separation between them and their statesmen.

In paragraph three, it was alleged that some Western politicians have been scheming to depict Islam as a harrowing and horrific religion worldwide. In order to justify his utterances and arguments in paragraph three and to convince his addressees about 'Western governments' insincere and hypocritical treatment of other nations and cultures', the writer (in par. 5) overtly and intermittently utilizes rake-it-up strategies and disparaging remarks by dredging up some unpleasant past when some Western countries practiced slavery and colonialism long ago. He probably struggles to denigrate the west and to underscore and foregrounds Islamic thoughts and his notions instead.

To criticize the Western media's Anti-Islam propaganda, the writer (in para. 10) intimates to hold the West accountable for the creation of DAESH (ISIS) and claimed that this group or any other terrorist groups are their own accomplice and proxy recruited to disgrace Muslims and Islam, so that they have the pretext to blame Islam. He insinuated that the bloodsheds wrought in the name of Islam by those terrorists must not be attributed and generalized to the whole Muslims worldwide; and these terrorists and their savage and inhumane misdeeds and delinquencies are not only disapproved, reproached and demonized by all Muslims but also they are ostracized by the Muslims worldwide.

In referring to the West, his tone in $1^{\text {st }}$ letter is aggressive and tough but lenient, advisory and soft to the Youth; however in the $2^{\text {nd }}$ letter, his tone of voice is somewhat sharp toward the youth and is belligerent toward Israel and the West; overall he employs a more conciliatory tone throughout the letters, saying: 'Don't allow them [western countries] to hypocritically introduce their own recruited terrorists as representatives of Islam'. That is part of a persisting process and growing trend that, he wrote, began after 'the disintegration of the Soviet Union'. 'This is a preplanned challenge between Islam and you', he added, a twenty-year-long bid by the West 'to place this great religion in the seat of a horrifying enemy'.

\section{Critical \& Contextual Analysis of the Second Letter}

To van Dijk (2012) "discourses are like icebergs. Only a minor part of their meaning is 'visible' as explicit propositions expressed in their sentences. The major part of their meaning remains implicit, namely as implied propositions" (p. 596). Thus, we must be vigilant when we read, analyze or probe the discourse of politics to seek evidence of stage management, purposive and eclectic use of words and expressions, or even of contextual, lexicogrammatical, rhetorical devices and so on.

In his $2^{\text {nd }}$ letter, the writer referred to the strings of terrorist attacks in France as Blind terrorism adding that Palestinians are confronted with 'worst' terrorism. This concept is permeating through the letter and is named blind for some reasons. To him, primarily, it stems from the hypocrisy and duplicity of western policies, i.e. the domination of double-standards and contradictory policies of the west against terrorism in the support for the state-sponsored terrorism of Israel and in creating or at least reinforcing and arming vile and terrorist groups such as al-Qaeda, Taliban and their inauspicious successors, namely ISIS, as the epitome of unspeakable violence and profound religious intolerance. Thus, as he postulates:

So long as terrorism is compartmentalized by its powerful supporters into categories of 'good' and 'bad', and so long as governmental interests are given precedence over humane and ethical values, the roots of violence should not be sought in any other place.

The lead rationale behind it is the basic tenets and faith of DAESH which is believed to grow out of Wahhabism and begun after the colonialist era in Muslim world. The basics of DAESH or other extremists' notions is believed to be derived from Wahhabism who are ostracized by most Muslims; the majority of mainstream Sunni and Shia Muslims worldwide wholeheartedly disapprove of the interpretation of Wahhabism, and many Muslims would denounce them as a faction or a 'vile sect' (Valentine, 2015, p. 16). They are regarded as Pseudo-or-Quasi-Muslims who have brought disgrace on other Muslims. Their barbarous misdeeds, atrocious and brutal murdering, violent terrorist attacks and the like on defenseless and innocent civilians have escalated Islamophobia and added fuel to raging inferno of 
Islamophobic and Anti-Muslims sentiments amongst other nations. Their distorted and rejected thoughts and beliefs are regularly denounced by Muslims with terms such as satanic faith (Valentine, 2015). Those or other radical extremists stand accused of being a source of global terrorism riddling callously the bodies of both innocent Muslims and nonMuslims with bullets.

His first requests in both letters are somehow alike, i.e. he requested the youth to convert their current mentality corrupted by duplicity via the western media by studying and researching the 'incentives behind this widespread tarnishing of the image of Islam'. Finally, he insinuated that it is the task of the youth to analyze and uncover those hidden and apparent corruptions in various layers and façade of their own society and then to untangle any deep-rooted knots, resentments and chasms. However, they are warned not to take any superficial and extreme measures or any hysterical or knee-jerk reactions; otherwise it will do nothing.

Mr. Khamenei finishes his letters by appealing to the youth not to 'miss the opportunity to gain proper, correct and unbiased understanding of Islam' and to then 'write the history of this current interaction between Islam and the West with a clearer conscience and lesser resentment.' Despite the fact that the letters are written in response to the horrifying violence of Paris attacks, and instead of resisting violence, or embracing peace, he weirdly wishes youth to 'write history.' Unlike the $2^{\text {nd }}$ letter, the first letter contains no direct deprecation of extremism, violence and terrorism at all. He also concludes both letters with a blessing and an appeal to the Youth in the West not to permit to be confined and encircled 'with fabricated, mental borders' and offensive portrayal against Islam by the media or the West each of whom trying to establish a yawning chasm between them and reality, saying: 'Hopefully, due to your sense of responsibility toward the truth, future generations would write the history of this current interaction between Islam and the West with clearer conscience and lesser resentment.'

\section{CONCLUSION}

By drawing upon the recent theoretical framework of Burkean concept of ID in the corpus, the current research argues that ID is a fundamental component in determining the writer's overall success or failure in identifying with the target readers. Thereby, ID, as an all-embracing device to rhetoric, is considered a deliberate strategy as when the writer seeks to identify himself with the addressees. The analysis provided in the results and discussion section supports this argument, emphasizing how ID functions are essential for rhetoricians to be aligned with the grass roots in order to achieve their intended objectives. In case of ID functions' absence or inappropriate deployment, there can be negative effects for the writer, as was seen in the writer' rhetoric in the current study.

Rhetoric, to Burke's definition (1969a), can be addressed to the self and since persuasion requires addressees, one can be his own addressee by "cultivating certain ideas and images" (p. 38). These symbols can be keywords and expressions that hold a wide assortment of meanings or rhetorical assumptions. Upon presenting these symbols to an individual or groups, it is their choice to accept or reject the symbols and by doing so, i.e. accepting or rejecting, a variety of meanings associate with such symbols. Rhetoricians seeking to use the conception of subconscious ID would possibly resort to the plurality of rhetorical tropes and strategies that take advantage of symbolic acceptance and rejection of symbols.

As a symbolic rhetorical decision-making process, for ID to be the most effective and influential, the readers must make rhetorically conscious decisions to position and link these ID appeals to their identity and belief system. Thereby, ID functions, as a two-step process, can be coupled with decision-making process of establishing one's self/identity via what is dubbed by Burke (1969a) as a symbolic rhetorical procedure.

Mr. Khamenei attempts to transcend division, gain ID, and thus, achieve his intended purposes and goal in the corpus by employing a series of rhetorical strategies and techniques in his letters. In the process of identifying with one another, the writer and readers become 'substantially one' with a person other than their self or identity. To construe ID in new rhetoric, Burke (1969a) presents the concept of division. It is found that there is definitely a division between both parties in this given context. Rhetoric, for Burke, is meant to supersede division with ID. The function of ID, simultaneously, reminds both parties 'of their capacity to be unique as well as their individual locus of control' (Sinha \& Jackson, 2006). It is the identification of this division which assists both parties in clarifying the fundamental contradiction that they are unified, yet alienated, from one another (Rosenfeld, 1969).

Intending to attain ID with his addressees, the writer has utilized certain strategies and keywords, such as 'peace and security, bright future' etc. to tailor his properties to the properties of the addressees. This constant stream of symbol connectedness can establish an appeal for the good life via a process of transcendence, generating a symbol of perpetual rebirth on the subconscious level. Some ways this could be accomplished is through the already mentioned rhetorical we-group strategy and emotional appeals. For Burke (1969a) the quest for ID on a subconscious level occurs via the symbolic fashion of making rhetorical choices. As Ambrester (1974) contends "identity occurs through acceptance and rejection of various symbols", i.e. by unconsciously developing our personalities, we establish a sense of selfness via the acceptance and rejection of multiple symbols imposed on us by multiple rhetorical strategies and contexts.

The results also indicate that in analyzing $2^{\text {nd }}$ function of ID, it is important to establish a clear rhetorical enmity/challenge. Since it is a stimulating force in ID, the introduction of a common and symbolic threat/enemy, can help both opposing parties rally against it, and thus establish ID. In this case, the addressees are positioned in a state to symbolically accept or reject the writer's notions through common threat. 
The successful/unsuccessful exploitations of ID functions are not clearly and explicitly delineated by Burke. The results of this study indicate that using ID functions in political text/talk can be remarkably potent and effectual; however, a total lack of ID functions and/or inappropriate implementation of them in any text/talk can culminate ID in failure. Yet their great success or failure seemingly depends on the addressees. In either way, it is then up to the addressees to consciously put that decision into their selves or identities. Consubstantiation/ID, as a contributing and motivating factor, occurs when two entities are coalesced into a substance through mutual notions, points of view and properties.

Van Dijk (1993) regards discourse as a subconscious depiction of knowledge and all-embracing experience of the world constructing viewpoints, orientations, and ideology. Eventually, in light of van Dijk's socio-cognitive approach (2008), the researchers critically delved deeper into the letters and concentrated more on contextually-embedded entailments in the utterances, on connotative meanings of some expressions and words, as well as on deliberate disposition of emotionally, politically and religiously-charged terminology embedded within, between or behind the lines produced in the corpus by the writer.

The current research tried to provide a new insight into the prospective studies and outlines that for any political text/talk to successfully identify with the addressees, it requires to encompass at least two of ID functions/types in Burkean theory. The study hopes to smooth the path for prospective similar studies in political or other discourses; and for the goal of critical and rhetorical studies, the current research attempted to set out a manner in which a written/spoken discourse could be dissected and appraised lexico-grammatically, critically, and rhetorically through content and form deploying Burkean concept of ID along with its various strategies, tropes and types. 


\section{APPENDIX}

A quick review and synopsis of the $2^{\text {nd }}$ letter is as follows:

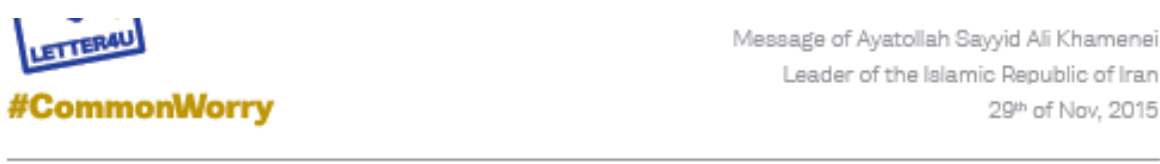

Review of maln toples In letter of Leader of Revolution to the youth In western countrles 29 Now. 2015

\begin{tabular}{|c|c|c|}
\hline 1 & Grounds of the words & $\begin{array}{l}\text { The bitter events brought about by blind terrorism in France have once again, moved } \\
\text { me to speak to you young people. }\end{array}$ \\
\hline 2 & $\begin{array}{l}\text { Main topics:Terroriam, } \\
\text { common worry }\end{array}$ & $\begin{array}{l}\text { Mutual consultation about terrorism as our common worry and finding solution for } \\
\text { a more secure future }\end{array}$ \\
\hline 3 & $\begin{array}{l}\text { Difference of terroriam in } \\
\text { west and lilamic world }\end{array}$ & $\begin{array}{l}\text { 1. Islamic world has been the victim of terror and brutality to a larger extent } \\
\text { territorially, to greater amount quantitatively and for a longer period in terme of time. } \\
\text { 2. Terroriam in lalamic world has always been supoorted by certain great powerg; e.g. } \\
\text { nurturing and arming of al-Qaeda, the Taliban and their inauspicious aucceesors by } \\
\text { US. }\end{array}$ \\
\hline 4 & Duplicity of western policies & $\begin{array}{l}\text { 1. Suppressing most pioneering democraciea, while allying with most backward } \\
\text { political aystems in region } \\
\text { 2. Double standards towards awakening movement in lalamic world } \\
\text { 3. Supoorting atate terroriam of larael despite its massacres and destructions in } \\
\text { Palestine } \\
\text { 4. Calling on Mualme not to view themselves as oppressed despite western military } \\
\text { invasiona of lslamic world in recent years }\end{array}$ \\
\hline 5 & $\begin{array}{l}\text { Firat step in creating } \\
\text { security }\end{array}$ & reforming western violence-breeding mentality \\
\hline 6 & $\begin{array}{l}\text { Real roots of violence in } \\
\text { weat }\end{array}$ & $\begin{array}{l}\text { 1. Dominance of double-standards over weetern policies } \\
\text { 2. Dividing terroriam into "good" and "bad" } \\
\text { 3. Preferring governmental interests over human values and ethics }\end{array}$ \\
\hline 7 & $\begin{array}{l}\text { Reeult of ill-fated pairings } \\
\text { with imported cultures }\end{array}$ & $\begin{array}{l}\text { - Silent violence and harmfulnees due to imposition of weetern culture upon other } \\
\text { nations } \\
\text { Humiliation of rich cultures by west deapite lack of replacement quality in weatern } \\
\text { culture which has two elements of "aggreesion" and "moral promiacuity" }\end{array}$ \\
\hline 8 & $\begin{array}{l}\text { Examples of ill-fated } \\
\text { pairinge with imported } \\
\text { cultures }\end{array}$ & $\begin{array}{l}\text { Planting seed of extremism in a Bedouin tribe since confluence of colonialism } \\
\text { with extremist thoughts } \\
\text { Formation of such garbage as DAESH due to unsucceseful tiea between imported } \\
\text { cultures }\end{array}$ \\
\hline 9 & $\begin{array}{l}\text { Why some Europeans join } \\
\text { terrorist groups }\end{array}$ & $\begin{array}{l}\text { - Being nurtured in a pathologic western culture in a corrupt environment borne out } \\
\text { of violence } \\
\text { Deep hate borne out of inequality and prejudice in west which appears in a } \\
\text { sickening marner }\end{array}$ \\
\hline 10 & $\begin{array}{l}\text { Big mistake in fight againat } \\
\text { terroriam }\end{array}$ & Rushed, emotional reactions and superficial mesaures \\
\hline 11 & $\begin{array}{l}\text { Consequences of hasty } \\
\text { reaction in fight against } \\
\text { terroriam }\end{array}$ & $\begin{array}{l}\text { Widening the chasme } \\
\text { - Creating iaolation, fear and anxiety among Musilma in Europe and America } \\
\text { - Depriving Muslims in Europe and America of their basic rights } \\
\text { a Opening the way for future crises by increasing current polarizations especialy } \\
\text { turning auperficial measures into legal forms }\end{array}$ \\
\hline 12 & $\begin{array}{l}\text { Musts in avoiding unjust } \\
\text { behavior with Muslims }\end{array}$ & $\begin{array}{l}\text { - Injustice brings unwanted reveraibility } \\
\text { - Muslims do not deserve auch il-treatment }\end{array}$ \\
\hline 13 & $\begin{array}{l}\text { Backgrounds of interaction } \\
\text { between weet and Muslims }\end{array}$ & $\begin{array}{l}\text { The day that westerners were guests in lalamic lands and were attracted to the } \\
\text { riches of their hoets and on another day when they were hosts and benefitted } \\
\text { from the efforts and thoughts of Muslimg-they generally experienced nothing but } \\
\text { kindness and forbearance. }\end{array}$ \\
\hline 14 & $\begin{array}{l}\text { Way to a bright, secure } \\
\text { future }\end{array}$ & $\begin{array}{l}\text { Disentangling and reeolving the knots and reaentments in western communities } \\
\text { - Laying the foundations for a correct and honorable interaction with the lalamic } \\
\text { world based on correct understanding, deep insight and leserne learned from } \\
\text { horrible experiences. }\end{array}$ \\
\hline
\end{tabular}

\section{REFERENCES}

[1] Abrams, M. H., \& Harpham, G. G. (2009). A Glossary of Literary Terms. Boston: Wadsworth Cengage Learning.

[2] Ambrester, R. (1974). Identification within Kenneth Burke's view of the unconscious. Philosophy \& Rhetoric, 7(4), $205-216$. Retrieved April 10, 2020, from http://www.jstor.org/stable/40236908.

[3] Atkins, J., \& Finlayson, A. (2014). 'As Shakespeare so Memorably Said...': Quotation, Rhetoric, and the Performance of Politics. Political Studies, 64(1), 164 - 181. 10.1111/1467-9248.12156.

[4] Bitzer, L. (1980). The Rhetorical Situation. Philosophy and Rhetoric, 1, 1- 14. Retrieved April 10, 2020, from http://www.bhsu.edu/Portals/201/Bitzer--Rhetorical\%20Situation.pdf.

[5] Burke, K. (1937). Attitudes toward history ( $3^{\text {rd }}$ ed.). Belkeley: University of California Press. 
[6] Burke, K. (1951). Rhetoric-Old and New. The Journal of General Education. 5(3), 202-209. Retrieved April 10, 2020, from http://www.jstor.org/stable/27795349.

[7] Burke, K. (1969a). A Rhetoric of Motives ( $2^{\text {nd }}$ ed.). Belkeley: University of California Press.

[8] Burke, K. (1969b). A Grammar of Motives ( $2^{\text {nd }}$ ed.). Berkeley \& Los Angeles: University of California Press.

[9] Cheney, G. (1983). The rhetoric of identification and the study of organizational communication. Quarterly Journal of Speech, 69(2), 143-158.

[10] Chilton, P. A. (2004). Analyzing Political Discourse: Theory \& Practice. London: Routledge.

[11] Christiansen, J. (2014). Identification: The Missing Link within the Rhetoric of Social Movements (Unpublished master's thesis). Manhattan: Kansas State University. Retrieved April 10, 2020, from http://krex.k-state.edu/dspace/handle/2097/17678

[12] Corbett, E. (1998). Classical rhetoric for the modern student, New York: Oxford University Press.

[13] Day, D. G. (1960). Persuasion and the concept of identification. Quarterly Journal of Speech, 46(3), $270-273$. http://dx.doi.org/10.1080/00335636009382421.

[14] Ehninger, D. (1975). A Synoptic View of Systems of Western Rhetoric. Quarterly Journal of Speech, 61(4):448-453. http://dx.doi.org/10.1080/00335637509383307.

[15] Flowerdew, J. (2002). Rhetorical strategies and identity politics in the discourse of colonial withdrawal. Journal of Language and Politics, 1(1), 149-180. https://doi.org/10.1075/jlp.1.1.09flo.

[16] Foss, S. K., Foss, K. A. \& Trapp, R. (2001). Contemporary Perspectives on Rhetoric ( ${ }^{\text {rd }}$ eds.). Waveland press, Inc.

[17] Griffin, L. M. (1952). The Rhetoric of historical movements. Quarterly Journal of Speech, 38(2), $184-188$. http://dx.doi.org/10.1080/00335635209381762.

[18] Hansen, G. (1996). Kenneth Burke's Rhetorical Theory within the Construction of the Ethnography of Speaking. Folklore Forum, 27(1), 50-59.

[19] Hart, R. P., \& Daughton, S. (2005). Modern Rhetorical Criticism. (3 $3^{\text {rd }}$ ed.). Boston: Pearson.

[20] Harte, T. B. (1977). The concept of identification in the rhetorical theories of Kenneth Burke and Eric Hoffer. Communicator, 7(2), 64-69

[21] Herrick, J. A. (2013). A History and Theory of Rhetoric: An Introduction. (5 $5^{\text {th }}$ ed.). New York: Routledge.

[22] Johnstone, B., \& Eisenhart, C. (Eds.). (2008). Rhetoric in Detail: Discourse Analyses of Rhetorical Talk and Text. Amsterdam: John Benjamins Publishing. doi.org/10.1075/dapsac.31.

[23] Kazemian, B., \& Hashemi, S. (2014). Critical discourse analysis of Barack Obama's 2012 speeches: Views from systemic functional linguistics and rhetoric. Theory and Practice in Language Studies, 4(6), 1178-1187. DOI:10.4304/tpls.4.6.11781187.

[24] Kazemian, B., \& Hashemi, S. (2017). A Radical Shift to a Profound and Rigorous Investigation in Political Discourse: An Integrated Approach. International Journal of English Linguistics, 7(3), 115-128. doi.org/10.5539/ijel.v7n3p115.

[25] Lakoff, R. T. (1990). Talking Power: The Politics of Language in Our Lives. USA: BasicBooks.

[26] Li, Y. \& Chen, G (2015). The Application of Identification Strategies in Sci-fi Movie Avatar. International Journal of English Linguistics, 5(2), 123-131. doi.org/10.5539/ijel.v5n2p123.

[27] Murphy, J. M. (2003). "Our mission and our moment": George W. Bush and September 11th. Rhetoric \& Public Affairs, 6(4), 607-632. doi.org/10.1353/rap.2004.0013.

[28] Rex, J. (2011). The President's War Agenda: A Rhetorical View. Presidential Studies Quarterly 41(1), 93-118. doi:10.1111/j.1741-5705.2010.03832.x.

[29] Richardson, J. E. (2004). (Mis) Representing Islam: The Racism and Rhetoric of British Broadsheet Newspapers. Amsterdam: John Benjamins Publishing. doi.org/10.1075/dapsac.9.

[30] Rosenfeld, L. B. (1969). Set Theory: Key to the understanding, of Kenneth Burke's use of the term "Identification". Western Speech, 33(3), 175-183. Retrieved April 10, 2020, from http://dx.doi.org/10.1080/10570316909384575.

[31] Sinha, P. N. \& Jackson, B. (2006). A Burkean Inquiry into Leader-Follower Identification Motives. Journal of Culture \& Organization, 12(3), 233-247. doi.org/10.1080/14759550600865966.

[32] Stanovich, K. E. (1980). Toward an interactive-compensatory model of individual differences in the development of reading fluency. Reading Research Quarterly, 16(1), 32-71. DOI: 10.2307/747348.

[33] Thomas, L., \& Wareing. S. (2004). Language, Society and Power. London: Routledge.

[34] Valentine, S. F. (2015). Force and Fanaticism: Wahhabism in Saudi Arabia and Beyond. Oxford: Oxford University Press.

[35] Van Dijk, T. A. (2001). Critical Discourse Analysis. In D. Schiffrin, D. Tannen, \& H. E. Hamilton (eds.). (2015). The Handbook of Discourse Analysis ( $2^{\text {nd }}$ eds.) (pp. 352-371). Oxford: Blackwell.

[36] Van, Dijk, T. A. (1993). Principles of Critical Discourse Analysis. Discourse \& Society, 4(2), $249-283$. $10.1177 / 0957926593004002006$.

[37] Van Dijk, T. A. (2008). Discourse and Context: A sociocognitive approach. Cambridge: Cambridge University Press.

[38] Van Dijk, T. A. (2012). Discourse and knowledge. In J. P. Gee \& M. Handford (eds.). (2012). The Routledge Handbook of Discourse Analysis. (pp. 596-603). London: Routledge.

[39] Weaver, R. (1953). The ethics of rhetoric. Chicago: Henry Regnery.

[40] Woods, N. (2006). Describing discourse: A practical guide to discourse analysis. New York: Horder Education.

[41] Ziahosseiny, S. M. (1999). A contrastive analysis of Persian and English and error analysis. Tehran: Nashr-e Vira.

[42] Zhou, Q. \& Kazemian, B. (2015). A Rhetorical Identification Analysis of English Political Public Speaking: John F. Kennedy's Inaugural Address. International Journal of Language and Linguistics, 4(1-1), 10-16. 10.11648/j.ijll.s.2016040101.12.

Bahram Kazemian is a Ph.D. candidate and was born in Tabriz City, East Azerbaijan Province, Iran in 1979. He obtained his B.A. in English Translation and his M.A. in ELT from the Islamic Azad University-Tabriz branch, Iran. Currently, he is the managing director of Unique Language Center in Tabriz. He has 15 years of experience in TEFL at different language institutes in Tabriz. His major thrust areas of interest are Systemic Functional Linguistics, CDA, Rhetoric and Rhetorical Devices, Appraisal 
Framework in SFL, Metadiscourse Markers (Hedges, Boosters, etc.), ELT and EFL. He has published several articles, six ISI book reviews and one book based on his areas of interest. He serves as a member of Editorial Boards and Reviewers for various journals.

Shatha Naiyf Qaiwer obtained her Ph.D. at the university of Nottingham / UK - School of English. She is currently teaching at the University of Baghdad. Her major thrust areas of research interest are CDA, political discourse analysis and corpus studies.

Shafigeh Mohammadian is an MSc and was born in Tabriz City, East Azerbaijan Province, Iran in 1990. She obtained her MSc from Urmia University, Iran. She is currently teaching in Unique Language Centre. Her major thrust areas of rese arch interest are CDA and ELT. 